University of Montana

ScholarWorks at University of Montana

\title{
2-2014
}

\section{Invasive plant erodes local song diversity in a migratory passerine}

Yvette K. Ortega

USDA Forest Service

Aubree Benson

The University of Montana, aubreedog@yahoo.com

Erick Greene

University of Montana - Missoula, erick.Greene@mso.umt.edu

Follow this and additional works at: https://scholarworks.umt.edu/biosci_pubs

Part of the Biology Commons, Forest Biology Commons, and the Terrestrial and Aquatic Ecology Commons

Let us know how access to this document benefits you.

\section{Recommended Citation}

Yvette K. Ortega, Aubree Benson, and Erick Greene 2014. Invasive plant erodes local song diversity in a migratory passerine. Ecology 95:458-465. http://dx.doi.org/10.1890/12-1733.1

This Article is brought to you for free and open access by the Biological Sciences at ScholarWorks at University of Montana. It has been accepted for inclusion in Biological Sciences Faculty Publications by an authorized administrator of ScholarWorks at University of Montana. For more information, please contact scholarworks@mso.umt.edu. 


\title{
Invasive plant erodes local song diversity in a migratory passerine
}

\author{
Yvette K. Ortega, ${ }^{1,4}$ Aubree Benson, ${ }^{2}$ and Erick Greene ${ }^{3}$ \\ ${ }^{1}$ Rocky Mountain Research Station, USDA Forest Service, 800 East Beckwith Avenue, Missoula, Montana 59801 USA \\ ${ }^{2}$ College of Forestry and Conservation, Wildlife Biology Program, University of Montana, Missoula, Montana 59812 USA \\ ${ }^{3}$ Division of Biological Sciences, University of Montana, Missoula, Montana 59812 USA
}

\begin{abstract}
Exotic plant invasions threaten ecosystems globally, but we still know little about the specific consequences for animals. Invasive plants can alter the quality of breeding habitat for songbirds, thereby impacting important demographic traits such as dispersal, philopatry, and age structure. These demographic effects may in turn alter song-learning conditions to affect song structure and diversity. We studied Chipping Sparrows (Spizella passerina) breeding in six savannas that were either dominated by native vegetation or invaded by spotted knapweed (Centaurea stoebe), an exotic forb known to diminish food resources and reproductive success. Here, we report that the prevalence of older birds was relatively low in knapweed-invaded habitat, where recruitment of yearlings compensated for diminished site fidelity to sustain territory abundance. In both habitat types, yearling males tended to adopt songs similar to their neighbors and match the songs of older birds rather than introducing new song types, a pattern seen in many songbird species. As a consequence, in invaded habitat where age structure was skewed away from older birds serving as potential song models, yearlings converged on fewer song types. Similarity of songs among individuals was significantly higher and the overall number of song types averaged nearly $20 \%$ lower in invaded relative to native habitat. Degradation of habitat quality generally impacts site fidelity and age ratios in migratory songbirds and hence may commonly alter song-learning conditions. Associated shifts in song attributes known to influence reproductive success could in turn enforce demographic declines driven by habitat degradation. Local song structure may serve as an important indicator of habitat quality and population status for songbirds.
\end{abstract}

Key words: age structure; Centaurea maculosa; Centaurea stoebe; Chipping Sparrow; exotic plants; Lolo National Forest, western Montana, USA; savanna habitat; site fidelity; song diversity; song learning; Spizella passerina; spotted knapweed.

\section{INTRODUCTION}

Invasive plants represent a major threat to ecosystems worldwide (Mack et al. 2000). While negative impacts of exotic plant invasions on native plants have been studied extensively (Hejda et al. 2009), relatively little is known about consequences of associated habitat changes for animals, including songbirds. Some studies have found reduced abundance of songbirds breeding in invaded compared to native habitats, but few have looked beyond this measure to develop understanding of the interlinked ecological processes (Ortega et al. 2006), including potential effects on social interactions among birds. By impacting songbird habitat quality and associated demographic properties such as breeding dispersal and age structure, invasive plants may influence processes such as song learning and thereby alter local song structure and diversity. Although it is increasingly recognized that habitat degradation can impact acoustic signals in a range of animal taxa (Barber et al. 2010, Laiolo 2010), links between habitat

Manuscript received 10 October 2012; revised 1 July 2013; accepted 31 July 2013. Corresponding Editor: J. R. Sauer.

${ }^{4}$ E-mail: yortega@fs.fed.us degradation, demographic properties, and birdsong have only been examined a few times (Laiolo and Tella 2005, 2007, Laiolo et al. 2008).

There are several ways that invasive plants can alter the quality of breeding habitat for songbirds to shift demographic properties. By affecting food availability or nest predation levels, exotic plant invasion can impact reproductive success (Borgmann and Rodewald 2004, Lloyd and Martin 2005, Ortega et al. 2006). In turn, reproductive success can strongly influence fidelity to breeding sites (Hoover 2003). In migratory songbirds, low-quality habitats with high turnover of breeding adults are typically replenished by annual recruitment of yearlings dispersing from natal sites (Greenwood and Harvey 1982, Holmes et al. 1996). Thus, habitat degraded by invasive plants may be characterized not only by decrements in reproductive success and site fidelity, but also by reduced prevalence of older vs. yearling birds.

Given these potential effects on songbird demographic properties, exotic plant invasion may also alter songlearning conditions, impacting song transmission between generations and the maintenance of local song structure and diversity. In migratory songbirds, yearling males typically adopt a song that is similar to their 
territory neighbors on the breeding grounds (Beecher and Brenowitz 2005). Moreover, for many species including Chipping Sparrows, yearling males often match the song of older birds, which arrive on the breeding grounds first already possessing crystallized songs (Payne et al. 1988, Liu and Nottebohm 2007, Schook et al. 2008). Hence, the prevalence of older birds may constrain the local diversity of song types. In lowquality habitats where age ratios of migratory species are typically skewed away from older birds and towards yearlings, yearlings may have fewer song types to match, with more birds converging on the same song types. Thus, songs of individuals breeding in low-quality habitats may show increased similarity, amounting to diminished diversity of local song types.

Other forms of habitat degradation may influence song learning via shifts in demographic properties. Prior work on two lark species correlated habitat fragmentation and its deleterious effects on population size with increased song similarity (Briefer et al. 2010) and reduced song diversity (Laiolo and Tella 2005, 2007, Laiolo et al. 2008), likely stemming from declines in the number of song models. However, for migratory songbirds, decrements in habitat quality commonly cause more subtle changes in demographic properties, i.e., reduced site fidelity and/or skewed age ratios (Holmes et al. 1996, Hoover 2003, Habib et al. 2007), which are not necessarily accompanied by reduced territory density, particularly in the case of humaninduced habitat degradation (Bock and Jones 2004, Robertson and Hutto 2006). Yet we are unaware of studies examining how these more subtle demographic changes may impact local song attributes. While song learning may be sensitive to demographic properties commonly impacted by habitat degradation, resultant shifts in song attributes could in turn feed back to affect demographic properties such as reproductive success given that song mediates mate attraction and other important processes (Laiolo 2010). Hence, shifts in song attributes could enforce demographic declines associated with habitat degradation. Overall, more work is needed to understand the interaction between song and population processes in the context of habitat change.

The exotic forb spotted knapweed (Centaurea stoebe) has invaded vast areas of western North America (DiTomaso 2000). In addition to impacting structure and composition of native grassland communities, this plant has reduced food availability for songbirds such as Chipping Sparrows, which show diminished levels of reproductive success and site fidelity in knapweedinvaded compared to native-dominated sites (Ortega et al. 2006). In our present study, we predicted lower prevalence of older vs. yearling Chipping Sparrows in knapweed-invaded habitat relative to native habitat, and that this shift in age structure would lead to increased song similarity and reduced song diversity in the lowquality vs. high-quality habitat.

\section{Methods}

We studied Chipping Sparrows breeding in ponderosa pine (Pinus ponderosa)/Douglas-fir (Pseudotsuga menziesii) savannas located at elevations of $1300-1700 \mathrm{~m}$ on steep, south to west-facing slopes on the Lolo National Forest in western Montana, USA. Study sites were chosen to be as similar as possible in terms of topography and vegetation except that three sites were heavily invaded by spotted knapweed, while three sites were dominated by native vegetation and contained only trace levels of knapweed. Each study site was surrounded by montane coniferous forest and represented a discrete habitat patch (area, $9.5 \pm 1.71$ ha $[$ mean \pm SE]) for Chipping Sparrows given their affinity for open forest types and associated edges (Middleton 1998). Native herbaceous cover consisted of diverse forbs and bunchgrasses characterizing grasslands of the region (Ortega and Pearson 2005). Availability of nest sites, as measured by average density of trees and canopy cover of shrubs, did not differ between knapweed and native sites $(t<2.3, P>0.1, \mathrm{df}=4)$. At each site, we established a 6.0 -ha rectangular plot oriented perpendicular to the slope and marked with four $250-\mathrm{m}$ transects spaced $50 \mathrm{~m}$ apart. All study plots fell within $25 \mathrm{~m}$ of dense forest and were separated by $>1.5 \mathrm{~km}$ over a $135-\mathrm{km}^{2}$ area. Sampling was conducted in 2005 and 2006 except where noted.

Previous work conducted in the study area correlated invasion of spotted knapweed with steep declines in native forbs and bunchgrasses, and diminished densities of native seeds and insects that constitute major food resources for ground-foraging songbirds such as Chipping Sparrows (Ortega and Pearson 2005, Ortega et al. 2006). These resource declines amounted to reduced habitat quality for Chipping Sparrows breeding in knapweed-invaded vs. native sites, as supported by documented impacts on demographic properties (Ortega et al. 2006). To support the link between knapweed invasion and habitat quality in our present study, we quantified levels of major vegetation groups (spotted knapweed, native forbs, and native bunchgrasses) associated with resource declines in previous work by using comparable methods to estimate canopy cover in July 2005 ( $n=52$ plots of $5 \mathrm{~m}$ radius per site; Ortega et al. 2006).

We lured Chipping Sparrows (see Plate 1) into mist nets with playback of songs and copulation calls recorded locally, and marked each bird with a unique combination of one aluminum band and three color celluloid bands. Using molt limits (Froehlich 2003) and plumage criteria (Pyle 1997), we assigned adults to the yearling or older age class. From May to July each year we delineated territories via standard spot-mapping methodology (IBCC 1970), color-band observations, and nest locations. Mapping efforts extended to a $50 \mathrm{~m}$ wide buffer area surrounding each plot and were conducted independently of banding efforts to avoid effects of playback on territorial behavior. Each year, we 
banded $>85 \%$ of males associated with mapped territories.

Observers conducted searches twice a week for banded birds on study plots and within 50-m buffer areas to determine territory status. Banded males were classified as residents of a site in a given year if they were observed in a mapped territory within plot boundaries during at least two different visits spaced at least two weeks apart $(>75 \%$ of residents were also positively associated with a nest located on the plot). To evaluate site fidelity in a given year, we distinguished those residents from the prior year that returned to the site (observed within plots or surrounding 50-m zones) from those that did not. To determine return rates for 2005 , we took advantage of birds marked and censused in 2004 as part of a related study that used the same methods outlined above. Our search protocol accounted for local dispersal of resident birds between seasons, i.e., when territories shifted within the same study site (Ortega et al. 2006), as typical Chipping Sparrow territories are circular, $<50 \mathrm{~m}$ in radius, and exclude dense forest, which surrounded study sites (Middleton 1998). Given our intensive search protocol, we assumed that between-year resighting probabilities were reasonably high, i.e., most birds not observed within the search area had dispersed from the sites or died. More importantly, because neither resighting probabilities nor annual survival are expected to differ markedly between knapweed-invaded and native habitats, return rates should provide a valid index of site fidelity (Ortega et al. 2006).

Male Chipping Sparrows learn a single song type consisting of one syllable repeated in a trill of varying length (Middleton 1998). As seen in many migratory songbirds, yearlings tend to match their song to neighbors on the breeding grounds, and do not change their song once crystallized (Beecher and Brenowitz 2005, Liu and Kroodsma 2006, Liu and Nottebohm 2007). Throughout the breeding season, we recorded songs beginning at sunrise using Sony TCM-5000 tape recorders, Sennheiser ME 66 shotgun microphones (Sennheiser Electronic Corporation, Old Lyme, Connecticut, USA), and Mineroff Electronics pre-amplifiers (Saul Minehoff Electronics, Elmhurst, New York, USA). Overall, we recorded songs for $>96 \%$ (159 of $165)$ of territorial males across years. Of those males recorded in both years $(n=44)$, none changed their song between years. We generated an average of $15 \pm 1.2$ song spectrograms per territorial male using Syrinx 2.6h (a downloadable Windows program for spectral analysis, editing, and playback of acoustic signals, developed by John Burt) with a sampling rate of $22.05 \mathrm{kHz}$, a $512-$ point FFT (fast Fourier transform) size, and a low dynamic range (near $35 \mathrm{~dB}$ ). We selected the highest quality recording per male for further analysis, and measured the following frequency and temporal variables for three randomly chosen syllables from each selected spectrogram: minimum frequency, maximum frequency, frequency range (maximum minus minimum), syllable duration, and inter-syllable interval (Fig. 1A). To account for qualitative differences between songs apparent through visual inspection, we also recorded the following variables: presence of a rapidly modulated trill, presence of a mid-syllable break, number of frequency shifts, and three variables collectively describing the type of frequency shift (Fig. 1B). The same observer measured and scored all songs.

\section{Statistical analyses}

Analyses were conducted with SAS software (SAS Institute 2009). All response variables were evaluated using generalized linear mixed models (PROC GLIMMIX) with a normal distribution unless otherwise specified. Habitat type (i.e., knapweed-invaded vs. native) and year were treated as fixed factors in all models. Year effects including associated interactions were not reported unless significant at $P<0.05$. We reported least-squares means and standard errors derived from mixed models. To compare vegetation variables between habitat types, we accounted for spatial autocorrelation among plots at each site using a spherical spatial covariance term. We assessed annual territory density per site with a model that included the response per year as a repeated measure. For remaining tests of demographic parameters, we treated the individual bird as the independent sampling unit. To assess whether the probability of territorial males returning vs. not returning to sites (binary distribution) differed by habitat type, we included the annual response per individual as a repeated measure; in a separate model, we also included age and its interactions with habitat type as fixed factors. We used the same basic model to test whether the prevalence of older vs. yearling territorial males differed between habitat types.

To assess similarity among songs of territorial males, we used a principal-components analysis (PCA) that incorporated derived frequency, temporal, and qualitative variables. Using the first five PCs, which explained $>80 \%$ of the total variation, we calculated Euclidean distances between pairs of songs in PC space and treated this as our index of song similarity in all analyses. We compared this index of song similarity between invaded and native habitat using two models. In both models, we included the individual as a random factor, thereby treating each territorial male as the independent sampling unit. In the first model we considered song similarity among all pairs of resident males per site and year to test for overall differences between habitat types. In the second model we added fixed factors to examine other variables potentially influencing song similarity. Specifically, we compared song similarity between neighbors (territory centers $<100 \mathrm{~m}$ apart) and nonneighbors for each resident male per study site and year, and included a neighbor $\times$ habitat type interaction to test whether neighbor effects differed in invaded compared to native habitat. To control for covariance 


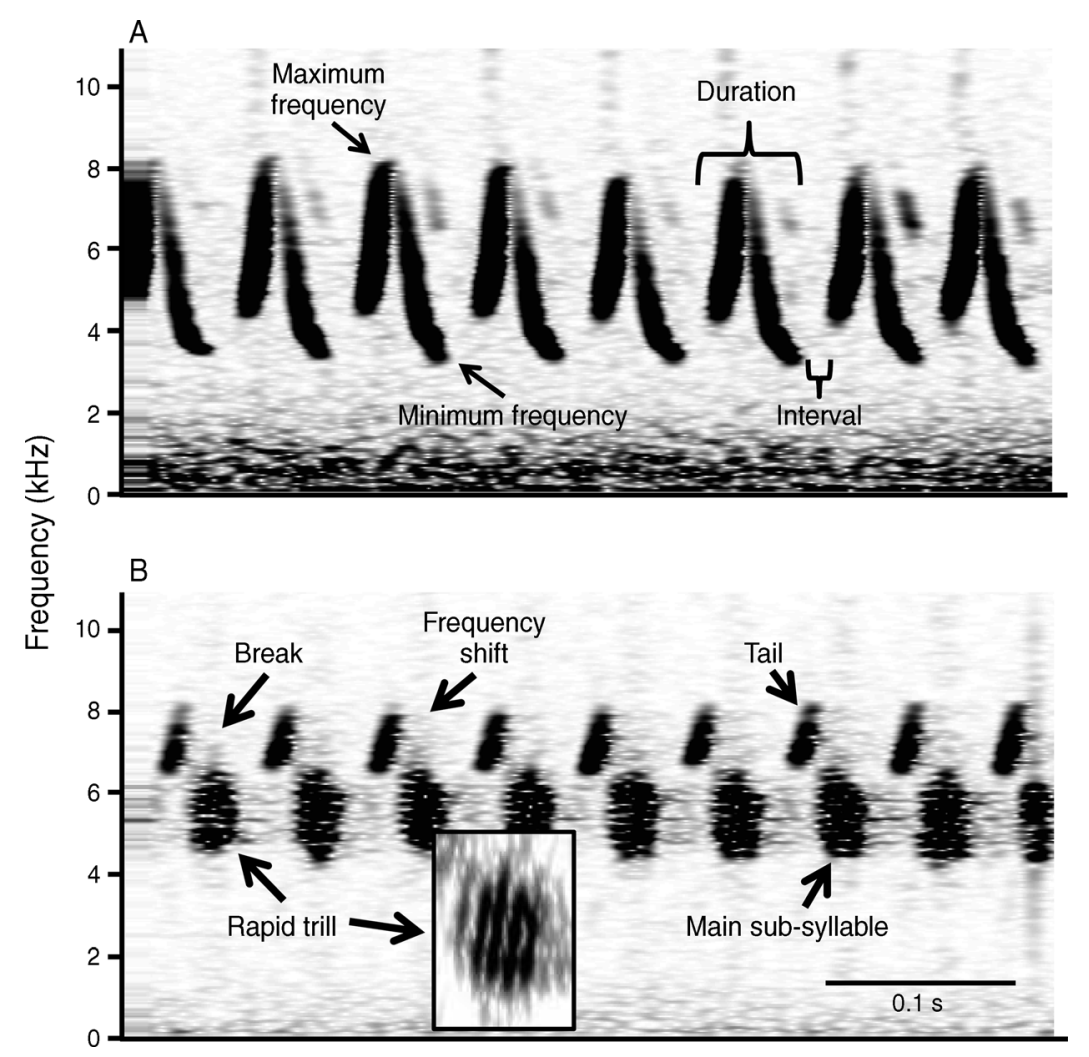

FIG. 1. Spectrogram of a Chipping Sparrow (Spizella passerina) song (0.5-s clip) depicting (A) frequency and temporal variables, and (B) qualitative variables used to determine song similarity and the number of song types. Three variables collectively described the type of frequency shift as follows: main sub-syllable ascending in frequency over time, descending in frequency, or neither; tail following the main sub-syllable or not; and tail present at the high end of the frequency range or not. The song pictured in (B) has one frequency shift and a main sub-syllable with no change in frequency, preceded by a tail at the high end of the frequency range. The inset details a rapidly modulated trill, as visualized at enhanced time resolution. See the Appendix for examples of all song types.

within each set of neighbor and non-neighbor comparisons per bird and year, we included the individual $x$ neighbor $\times$ year interaction as a random factor. Additionally, we examined the influence of focal male age on song similarity by including age and its interactions with habitat type and neighbor as fixed factors.

To consider how the degree of individual-level song similarity influenced song diversity at the site level, we hierarchically clustered (PROC CLUSTER) songs of all territorial males across years into distinct song types based on the five PCs that measured song similarity. We used the average linkage clustering method, and picked the 17-cluster solution (Appendix) based on standard criteria (cubic clustering criterion, pseudo- $F$ statistic, pseudo- $t^{2}$ statistic; SAS Institute 2009). Each cluster represented a unique song type in all analyses of song types. To compare the number of song types between invaded and native habitat, we treated the site as the independent sampling unit by specifying the response per year as a repeated measure. We compared the number of song types represented by older birds to those contributed uniquely by yearlings, using the same model structure with the addition of age and the age $\times$ habitat type interaction as fixed factors. Finally, to examine song matching at the individual level, we used a model with no random factors to test for between-habitat differences in whether or not yearling males matched song types represented by older birds on the site in each year (binary distribution).

\section{RESUlts}

Spotted knapweed cover was higher in invaded habitat $(16.4 \% \pm 3.64 \%$ [least-squares mean \pm SE] $)$ compared to native habitat $\left(0.4 \% \pm 3.64 \% ; F_{1,61}=9.7, P\right.$ $=0.003$ ), while cover of native forbs and bunchgrasses was lower in invaded (forbs, $11.0 \% \pm 1.86 \%$, bunchgrasses, $15.3 \% \pm 2.81 \%$ ) compared to native habitat (forbs, $20.3 \% \pm 1.85 \% ; \quad F_{1,30}=12.3, P=0.001$; bunchgrasses, $\left.41.7 \% \pm 2.8 \% ; F_{1,40}=44.1, P<0.001\right)$. Annual density of Chipping Sparrow territories did not differ between invaded $(25.2 \pm 1.34$ territories/10 ha) and native habitat $\left(24.7 \pm 1.34\right.$ territories $/ 10$ ha; $F_{1,4}=$ $0.07, P=0.8$ ).

Males breeding in invaded as opposed to native habitat showed reduced site fidelity, translating to a 


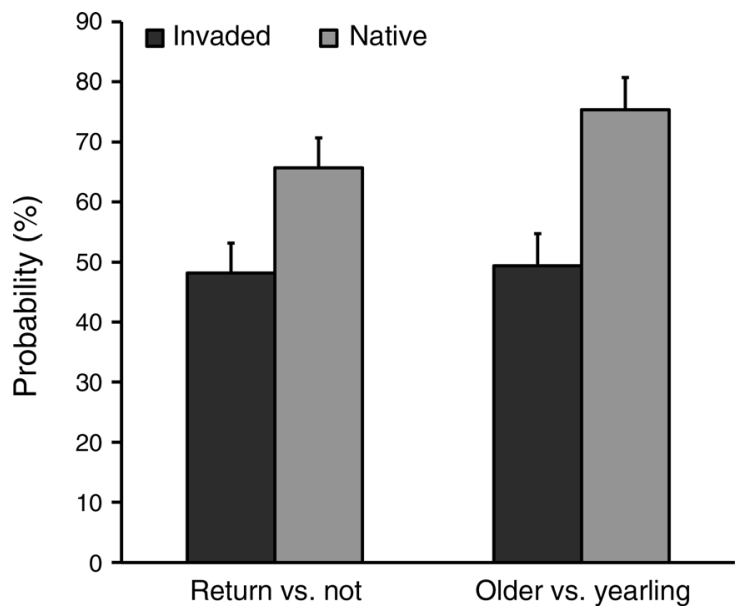

FIG. 2. Probability (least-squares mean + SE) of Chipping Sparrow males returning between breeding seasons and belonging to the older vs. yearling age class, as compared between knapweed-invaded and native habitat in western Montana, USA, 2005-2006.

lower prevalence of older vs. yearling birds (Fig. 2). The return rate for resident birds was lower in invaded habitat compared to native habitat $\left(F_{1,61}=4.4, P=\right.$ 0.041 ; Fig. $2 \mathrm{~A})$, and did not differ by age class $\left(F_{1,128}=\right.$ $0.8, P=0.36$ ) in either habitat type (habitat $\times$ age: $F_{1,128}$ $=0.0, P=0.99)$. Fewer males fell into the older as opposed to yearling age class in invaded relative to native habitat overall $\left(F_{1,74}=11.2, P=0.001\right.$; Fig. $\left.2 \mathrm{~B}\right)$, although this effect was stronger in $2005(46 \% \pm 7.3 \%$ vs. $85 \% \pm 5.2 \%)$ than in $2006(53 \% \pm 6.7 \%$ vs. $62 \% \pm$ $6.9 \%$; habitat $\times$ year, $F_{1,52}=6.5, P=0.012$ ).

Song similarity among resident males was higher in invaded $(3.4 \pm 0.06)$ relative to native habitat overall (3.1 $\left.\pm 0.05 ; F_{1,154}=15.5, P=0.001\right)$. Song similarity was higher for yearling compared to older birds $\left(F_{1,333}=7.0\right.$, $P=0.008)$, and the age effect did not differ between habitat types (age $\times$ habitat, $F_{1,328}=0.01, P=0.9$ ). In addition, song similarity was higher between neighbors than non-neighbors $\left(F_{1,292}=17.9, P<0.0001\right)$, with no difference in the neighbor effect by habitat type (neighbor $\times$ habitat, $F_{1,298}=0.02, P=0.89$ ). However, the neighbor effect was much stronger for yearling relative to older birds (neighbor $\times$ age, $F_{1,301}=4.2, P=$ 0.042; Fig. 3), and this effect did not differ between habitat types (neighbor $\times$ age $\times$ habitat, $F_{2,295}=1.3, P=$ $0.25)$.

Increased similarity among individuals in invaded habitat translated to diminished song diversity, as measured by the number of song types present on a site each year. The number of song types was lower in invaded $(7.6 \pm 0.29$ songs $)$ relative to native sites $(9.2 \pm$ 0.29 songs; $F_{1,4}=15.5, P=0.017$ ) by nearly $20 \%$. The probability of yearlings matching song types represented by older birds vs. contributing novel song types did not differ between invaded and native habitat $\left(F_{1,61}=0.0, P\right.$ $=0.95)$, and averaged $65 \%$ in both habitat types $(65 \% \pm$

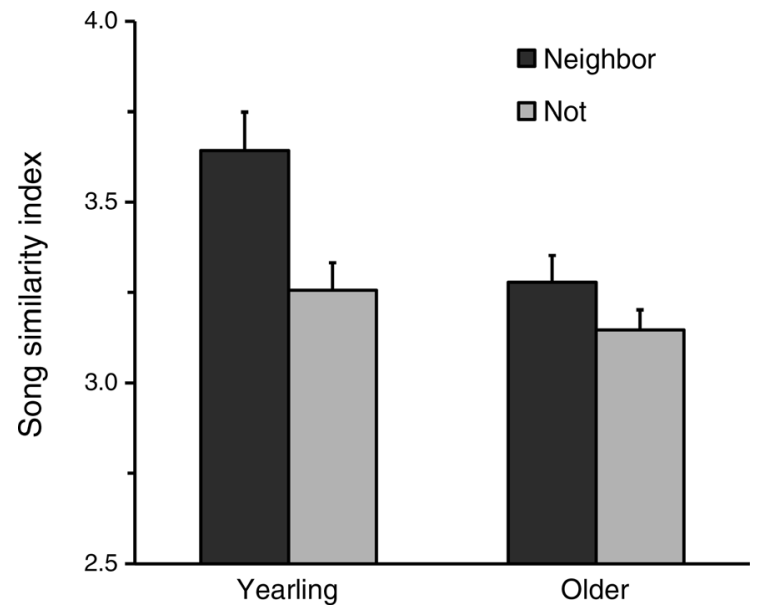

FIG. 3. Song similarity (least-squares mean $+\mathrm{SE}$ ) compared between neighbor and non-neighbor male Chipping Sparrows, by age class, across knapweed-invaded and native habitat in western Montana, USA, 2005-2006. The least-squared mean for each category accounts for data from males breeding in both knapweed-invaded and native sites (habitat), i.e., it was derived from the neighbor $\times$ age interaction. Song similarity was indexed using a PCA of acoustic and qualitative variables (see Methods).

$7.3 \%$ in invaded habitat and $65 \% \pm 12.1 \%$ in native habitat). Therefore, yearlings as a group contributed far fewer song types relative to older birds $\left(F_{1,4}=123.7, P=\right.$ $0.0004)$, with a weak tendency towards a smaller age effect in invaded habitat (age $\times$ habitat, $F_{1,4}=5.0, P=$ 0.089; Fig. 4). Notably, the average number of song types introduced by yearlings was low in both habitat types despite the fact that yearlings tended to be more common in invaded habitat. This was likely due to the fact that those yearlings introducing novel song types

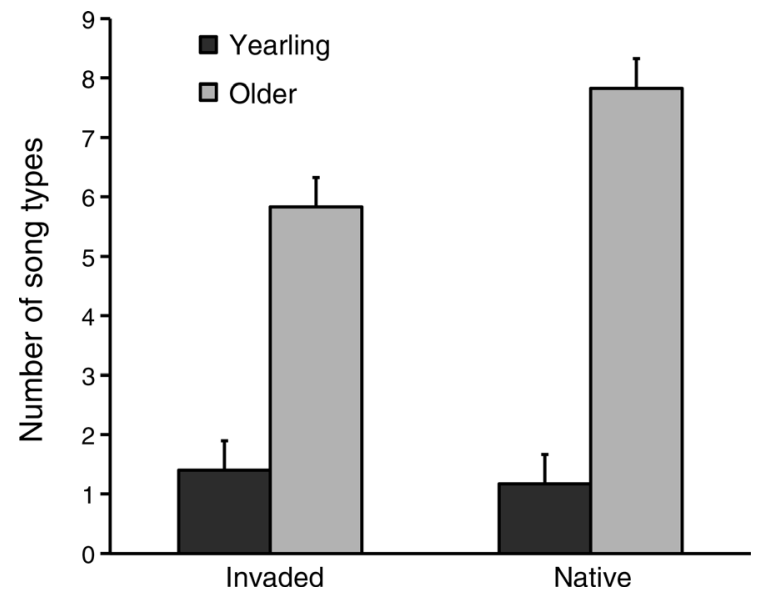

FIG. 4. Number of song types (least-squares mean $+\mathrm{SE}$ ) per site contributed by yearling compared to older Chipping Sparrows breeding in knapweed-invaded vs. native habitat in western Montana, USA, 2005-2006. Song types were determined using hierarchical clustering of PCs derived from acoustic and qualitative variables (see Methods). 


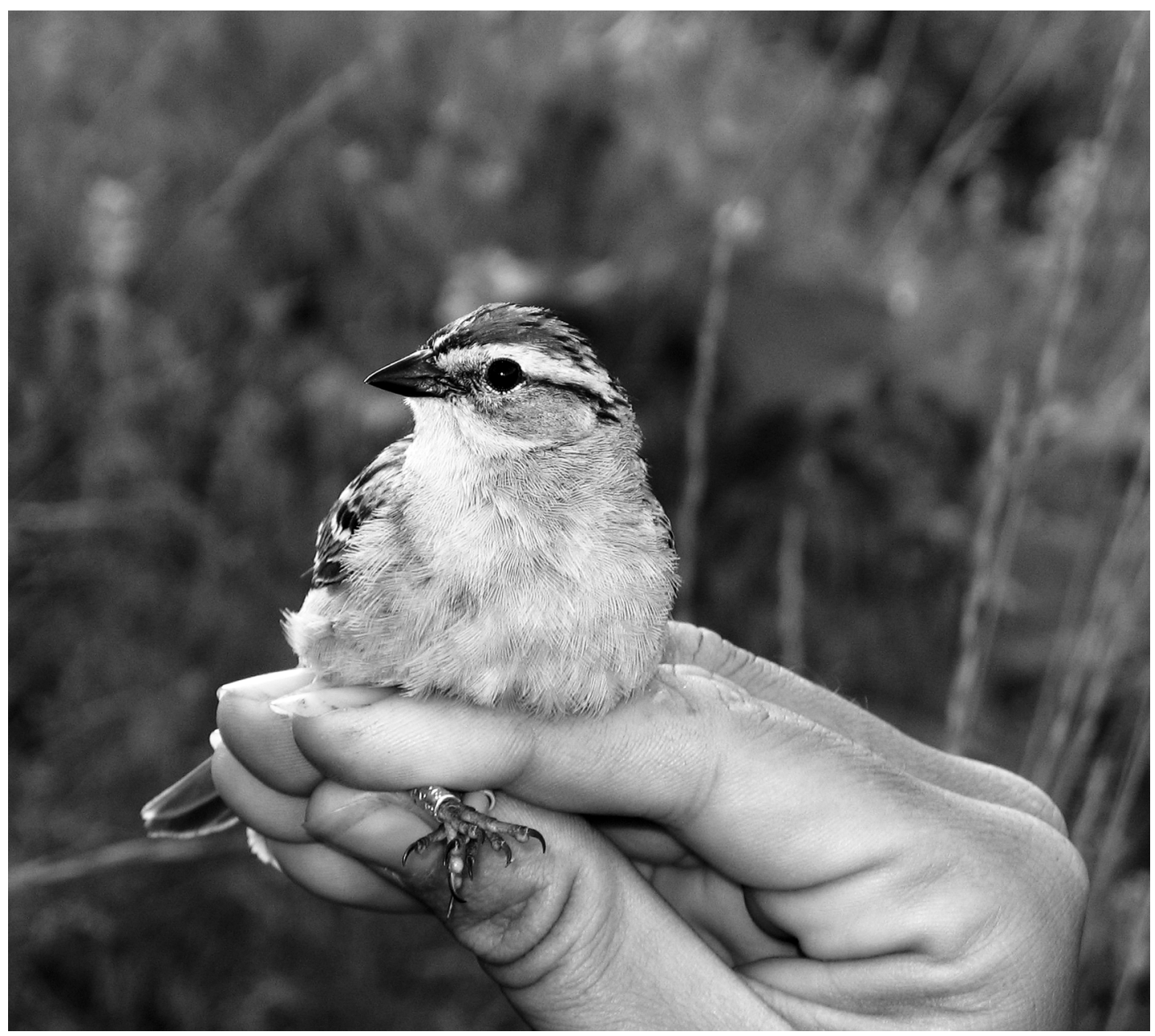

Plate 1. Adult Chipping Sparrow, banded to allow individual identification. Photo credit: A. Benson.

(i.e., not sung by older birds) shared song types with other yearlings in $75 \%$ of cases in invaded habitat, but never shared song types with other yearlings in native habitat (Fisher's exact test: $P=0.001, n=23$ birds). Overall, the probability of yearlings matching the song type of other resident birds vs. adopting a unique song type was higher in invaded $(92 \% \pm 4.2)$ relative to native habitat $\left(65 \% \pm 12.1 \% ; F_{1,61}=5.4, P=0.024\right)$.

\section{DiscusSION}

These results support our hypothesis that impacts of an invasive plant on demographic properties of a migratory passerine may erode song diversity. Habitat degradation by spotted knapweed influences site fidelity and age structure in Chipping Sparrows. These demographic changes appear to alter local song-learning conditions, resulting in increased similarity among songs and fewer song types overall. Together with previous work encompassing four additional study sites (Ortega et al. 2006), our results show that Chipping Sparrows breeding in knapweed-invaded vs. native habitats have degraded food resources, lower fecundity, and reduced fidelity to breeding sites (Ortega et al. 2006). Reduced site fidelity in knapweed-invaded habitat allows for increased recruitment of yearling males, as evidenced by the lower prevalence of older relative to yearling males in this habitat type. Although the magnitude of the age effect varied between years, the pattern was nonetheless consistent across years. These results parallel a strong body of research on migratory songbirds linking low habitat quality to reduced site fidelity and diminished ratios of older vs. yearling birds (Bollinger and Gavin 1989, Holmes et al. 1996, Hoover 2003, Habib et al. 2007, Noa et al. 2007).

The demographic shift in knapweed-invaded habitats appeared to influence local song structure, likely reflecting the role of age in the song-learning process. In the first few days after arrival on the breeding grounds, yearling Chipping Sparrows adopt their signature song by modifying precursor songs to resemble nearby males; during this brief period, encounters with older birds, which already possess crystallized songs and established territories, appear to be particularly influential (Liu and Kroodsma 2006, Liu and 
Nottebohm 2007). We found that for yearlings in particular, songs were more similar to territory neighbors than to non-neighbors. Moreover, $65 \%$ of yearlings adopted a song type already possessed by an older bird at their site. Due to this pattern of song matching, reduced prevalence of older males may have constrained song diversity in knapweed-invaded vs. native habitat. Indeed, similarity among individual songs was higher in knapweed-invaded habitat, translating to fewer song types per site. Similarly, yearlings were more likely to match the songs of other males in invaded compared to native habitat, further suggesting that song-learning conditions differed between habitat types.

Previous work has also related habitat degradation and the resulting demographic changes in songbird populations with diminished song diversity (Laiolo and Tella 2005, 2007, Laiolo et al. 2008, Briefer et al. 2010). These studies concluded that reduced population density along with diminished dispersal may result in fewer song models in fragmented vs. contiguous habitats, causing increased similarity among individual song repertoires and reduced repertoire sizes. Our study of a migratory songbird possessing a single, simple song suggests that reduced site fidelity and the associated shift in age structure induced by exotic plant invasion may also reduce the number of song models, and result in increased song similarity and fewer song types in invaded habitat. Although we examined song diversity at only six sites, the observed pattern corresponds with predictions drawn from strong links between knapweed invasion, habitat quality, and songbird demographics discussed previously.

For migratory songbirds, degradation of habitat quality is generally expected to result in reduced site fidelity and lower prevalence of older birds that serve as song models (e.g., Holmes et al. 1996). How these subtle demographic changes may affect song diversity likely depends on particular features of song learning, including the scale at which song matching occurs. While song matching in Chipping Sparrows occurs primarily at the neighborhood scale (Liu and Kroodsma 2006), many other species possess dialects where specific song types are clustered over relatively broad geographic areas (Beecher and Brenowitz 2005). The maintenance of dialects requires high fidelity to breeding sites (Nelson et al. 2001). Therefore, for dialect species, diminished site fidelity may impede song conformity. Similarly, a lack of older birds may promote increased divergence among local songs and erosion of established song types (Payne et al. 1988, Gammon et al. 2005). Hence, the same demographic factors linked to reduced song diversity in Chipping Sparrows could have the opposite effect in species or populations with dialects or otherwise differing song-learning programs.

Our results suggest that song attributes dependent on transmission between generations may be sensitive to impacts of exotic plant invasion on demographic properties of a migratory songbird. Similarity among individual songs increased in knapweed-invaded habitat at the expense of song-type diversity. This work expands on recent studies of songbirds documenting impacts of habitat fragmentation and associated population declines on song repertoires. More generally, habitat degradation may set in motion processes whereby shifts in site fidelity and age ratios alone alter the songlearning environment. Resultant changes in song attributes could in turn feed back to enforce demographic declines in degraded habitats, given that song is an acoustic signal mediating important processes such as territory defense, mate attraction, and habitat selection (Slabbekoorn and Smith 2002, Beecher and Brenowitz 2005, Laiolo 2010). For example, high-quality females may avoid degraded habitats based on song signatures (Betts et al. 2008) to further impede reproductive success in these habitats. Song may serve as an important indicator of habitat quality and population status for migratory songbirds, but more work is needed to elucidate the particular links between song attributes, such as diversity, and demographic processes, such as reproduction and breeding dispersal, across a range of taxa.

\section{ACKNOWLEDGMENTS}

We appreciate the insightful input of C. Templeton, D. Kroodma, L. Baggett, and two anonymous reviewers on drafts of the manuscript. Many thanks to A. Zmud, B. Ogle, E. Rasmussen, L. Waller, S. Fuller, and T. Rodriguez for their hard work in the field. This research was supported by the Rocky Mountain Research Station.

\section{Literature Cited}

Barber, J. R., K. R. Crooks, and K. M. Fistrup. 2010. The costs of chronic noise exposure for terrestrial organisms. Trends in Ecology and Evolution 25:180-189.

Beecher, M. D., and E. A. Brenowitz. 2005. Functional aspects of song learning in songbirds. Trends in Ecology and Evolution 20:143-149.

Betts, M. G., A. S. Hadley, N. Rodenhouse, and J. J. Nocera. 2008. Social information trumps vegetation structure in breeding-site selection by a migrant songbird. Proceedings of the Royal Society B 275:2257-2263.

Bock, C. E., and Z. F. Jones. 2004. Avian habitat evaluation: Should counting birds count? Frontiers in Ecology and the Environment 2:403-410.

Bollinger, E. K., and T. A. Gavin. 1989. The effects of site quality on breeding-site fidelity in Bobolinks. Auk 106:584594.

Borgmann, K. L., and A. D. Rodewald. 2004. Nest predation in an urbanizing landscape: the role of exotic shrubs. Ecological Applications 14:1757-1765.

Briefer, E., T. S. Osiejuk, F. Rybak, and T. Aubin. 2010. Are bird song complexity and song sharing shaped by habitat structure? An information theory and statistical approach. Journal of Theoretical Biology 262:151-164.

DiTomaso, J. 2000. Invasive weeds in rangelands: species, impacts, and management. Weed Science 48:255-265.

Froehlich, D. 2003. Ageing North American landbirds by molt limits and plumage criteria. A photographic companion to the Identification Guide to North American Birds. Part I. Slate Creek Press, Bolinas, California, USA.

Gammon, D. E., M. C. Baker, and J. R. Tipton. 2005. Cultural divergence within novel song in the Black-capped Chickadee (Poecile atricapillus). Auk 122:853-871. 
Greenwood, P. J., and P. H. Harvey. 1982. The natal and breeding dispersal of birds. Annual Review of Ecology and Systematics 13:1-21.

Habib, L., E. M. Bayne, and S. Boutin. 2007. Chronic industrial noise affects pairing success and age structure of ovenbirds Seiurus aurocapilla. Journal of Applied Ecology 44:176-184.

Hejda, M., P. Pysek, and V. Jarosik. 2009. Impact of invasive plants on the species richness, composition and composition of invaded communities. Journal of Ecology 97:393-403.

Holmes, R. T., P. P. Marra, and T. W. Sherry. 1996. Habitatspecific demography of breeding Black-throated Blue Warblers (Dendroica caerulescens): implications for population dynamics. Journal of Ecology 65:183-195.

Hoover, J. P. 2003. Decision rules for site fidelity in a migratory bird, the Prothonotary Warbler. Ecology 84:416-430.

IBSS [International Bird Census Committee (IBCC). 1970. Recommendations for an international standard for a mapping method in bird census work. Audubon Field Notes 24:722-726.

Laiolo, P. 2010. The emerging significance of bioacoustics in animal species conservation. Biological Conservation 143: $1635-1645$.

Laiolo, P., and J. L. Tella. 2005. Habitat fragmentation affects cultural transmission: patterns of song matching in Dupont's Lark. Journal of Applied Ecology 42:1183-1193.

Laiolo, P., and J. L. Tella. 2007. Erosion of animal culture in fragmented landscapes. Frontiers in Ecology and the Environment 5:68-72.

Laiolo, P., M. Vogeli, D. Serrano, and J. L. Tella. 2008. Song diversity predicts the viability of fragmented bird populations. PLoS ONE 3(3):e1822.

Liu, W.-C., and D. E. Kroodsma. 2006. Song learning by Chipping Sparrows: when, where, and from whom. Condor 108:509-517.

Liu, W.-C., and F. Nottebohm. 2007. A learning program that ensures prompt and versatile vocal imitation. Proceedings of the National Academy of Sciences USA 104:20398-20403.

Lloyd, J. D., and T. E. Martin. 2005. Reproductive success of Chestnut-collared Longspurs in native and exotic grassland. Condor 107:363-374.
Mack, R. N., D. Simberloff, W. M. Longsdale, H. Evans, M. Clout, and F. A. Bazzaz. 2000. Biotic invasions: causes, epidemiology, global consequences, and control. Ecological Applications 10:689-710.

Middleton, A. L. 1998. Chipping Sparrow (Spizella passerina). Number 334. Pages 1-31 in A. Poole and F. Gill, editors. The Birds of North America. The Birds of North America, Philadelphia, Pennsylvania, USA.

Nelson, D. A., H. Khanna, and P. Marler. 2001. Learning by instruction or selection: implications for patterns of geographic variation in bird song. Behaviour 138:11371160.

Noa, L. A., D. H. Hirth, T. M. Donovan, and D. Cimprich. 2007. Demographic differences of Black-capped Vireos in two habitat types in central Texas. Journal of Wildlife Management 71:1042-1049.

Ortega, Y. K., K. S. McKelvey, and D. L. Six. 2006. Invasion of an exotic forb impacts reproductive success and site fidelity of a migratory songbird. Oecologia 149:340-351.

Ortega, Y. K., and D. E. Pearson. 2005. Weak vs. strong invaders of natural plant communities: assessing invasibility and impact. Ecological Applications 15:651-661.

Payne, R. B., L. L. Payne, and S. M. Doehlert. 1988. Biological and cultural success of song memes in Indigo Buntings. Ecology 69:104-117.

Pyle, P. 1997. Identification guide to North American birds. Part 1. Slate Creek Press, Bolinas, California, USA.

Robertson, B. A., and R. L. Hutto. 2006. A framework for understanding ecological traps and an evaluation of existing evidence. 87:1075-1085.

SAS Institute. 2009. SAS/STAT user's guide, version 9.2. SAS Institute, Cary, North Carolina, USA.

Schook, D. M., M. D. Collins, W. E. Jensen, P. J. Williams, N. E. Bader, and T. H. Parker. 2008. Geographic patterns of song similarity in the Dickcissel (Spiza americana). Auk 125: 953-964.

Slabbekoorn, H., and T. B. Smith. 2002. Bird song, ecology and speciation. Philosophical Transactions of the Royal Society B 357:493-503.

\title{
Supplemental Material
}

\author{
Appendix \\ Spectrograms of Chipping Sparrow song types used to evaluate song diversity (Ecological Archives E095-040-A1).
}

